\title{
Is it economically possible repowering Wind Farms. A general analysis in Spain
}

\author{
L. Castro ${ }^{1}$, A. Filgueira ${ }^{1}, \mathrm{M}^{\mathrm{a}}$ A. Seijo ${ }^{1}$, E. Muñoz $^{1}$ and L. Piegiari ${ }^{2}$ \\ ${ }^{1}$ Department of Industrial Engineering II University of A Coruña, Ferrol-Spain, almudena@cdf.udc.es \\ ${ }^{2}$ Department of Electrical Engineering. Politecnico di Milano, Milan, Italy, luigi.piegiari@polimi.it
}

\begin{abstract}
Protecting the environment is becoming a major concern; people are beginning to realise that their living conditions may worsen if they do not rationalise energy use and habits. Environmental pollution and emissions from greenhouse gases caused by fossil fuel use are a threat to sustainable development. With renewable energy sources, no polluting emissions are released into the atmosphere. Therefore, using these sources on a large-scale is a key to reducing emissions and meeting the commitments established by the Kyoto Protocol. At the same time, renewable energy contributes to sustainable development.

This study describes economic aspects of the repowering process for the wind farms. This process was the result of a growing demand for renewable energies, facilitated by the great potential of wind energy in the north of Spain. The wind farms studied in this work were set up before 1998 and they have obsolete machinery with low power.
\end{abstract}

Key words-- repowering, viability study, wind farms, sensibility analysis.

\section{INTRODUCTION}

Repowering a wind farm entails revamping its installations with the aim of extending its service life and/or increasing its power, performance or availability and increasing, modifying and /or updating the equipment for optimum capacity or efficiency.

Given the constant advances made in wind and generator technology, it is now possible for the same site to have a much higher energy production with new machines. They are quieter, their efficiency is higher $(2$ or $3 \mathrm{MW})$, and their start-up speed (winds of $2.5-3 \mathrm{~m} / \mathrm{s}$ ) are much lower when compared with older turbines (0.1-0.65 $\mathrm{MW}$, with start-up wind speeds of $5 \mathrm{~m} / \mathrm{s}$ ).

Moreover, higher hubs on the new machines make it easier to exploit the wind at great heights. For this reason, repowering a wind farm leads to a noticeable increase in farm production, although the number of generators installed is reduced.

With repowering it is possible to generate considerably more electric current with fewer installations. On the other hand, as the new installations work at lower speeds, their appearance is more calming. It is easier to connect them to the electric grid given that their connection behaviour is similar to that of conventional power plants. This makes their utilisation more feasible.
Therefore, repowered sites are:

- $\quad$ More productive with fewer machines.

- $\quad$ Less difficult to integrate into the grid.

- $\quad$ Easier on the ear and eye.

- The maintenance costs for air generators with over ten years of service increase by $25 \%$. Replacing machines after ten years, once initial costs have been recovered, makes it possible to have newer and more advanced equipment for a significant number of years.

The first wind farms used the highest wind measurements; nowadays production can be greater.

\section{REPOWERING THE WIND FARMS}

\section{STUDYING THE ALTERNATIVES}

Parks under study have a similar power because are those built as late in the year 1998 .

A technical and economic feasibility study on the repowering process is carried out and various alternatives are considered: A, B, C, D, E, F, G, H and I (see Table 1). For the second step, the relevant Spanish legislationRD 661/2007 of 25 May- must be taken into account; this regulates the activity of energy production within a special regime. It establishes that, for an increase of up to $40 \%$, a new license is not needed, providing that the transmission power cited in the original permit is not exceeded. At first it might be thought that increasing the power by $100 \%$ is very profitable, and rightly so. Nevertheless, with the current system for issuing permits, it is extremely difficult to get a new one, despite the fact that repowering takes precedence.

Consequently, these are the options:

- OPTION 1: $\Delta \mathrm{P}<40 \%$ and the power does not exceed the electric power authorised

- OPTION 2: $\Delta \mathrm{P}=40 \%$ and the power exceeds the authorised electric power so that a new licence is needed.

- OPTION 3: $\Delta \mathrm{P}>40 \%$, specifically $\quad \mathrm{P}=50 \quad \mathrm{MW}$ (maximum production limit in the special regime), and the power exceeds the authorised limit, so that a new transmission limit is needed. 
- OPTION 4: $\Delta \mathrm{P}>40 \%$ the power exceeds the authorised limit, so that a new transmission limit is needed.

OPTION 3 is not possible in technical terms. The volume of wind generators that would need to be installed for this option is very high; they would not fit on the site given the minimum distances required between wind towers.

OPTION 4 was chosen instead. As many wind towers as technically possible will be installed, always bearing in mind that the maximum limit of 50 MW cannot be exceeded.

On the other hand, three models of wind generators with similar features will be studied: the N80 at $2.5 \mathrm{MW}$ from Nordex; the B80 at 2.3 MW from Bonus and the N90 at 2.3 MW from Nordex, all of which have towers that are $80 \mathrm{~m}$ high.

The four options mentioned above will be considered for each model. These options will also condition how many of each model is chosen. Given that the third is not viable, only OPTIONS 1, 2 and 4 will be examined.

There are, therefore, nine possible alternatives, indicated from A to I, as shown in the table below:

Table 1: Alternatives under study

\begin{tabular}{|l|l|l|}
\hline \multicolumn{3}{|l|}{ ALTERNATIVE } \\
\hline A & B & C \\
\hline N80 2..5 MW & \\
\hline OPTION 1 & OPTION 2 & OPTION 4 \\
\hline
\end{tabular}

\begin{tabular}{|l|l|l|}
\hline \multicolumn{3}{|l|}{ ALTERNATIVE } \\
\hline D & E & F \\
\hline B80 2..3 MW & \\
\hline OPTION 1 & OPTION 2 & OPTION 4 \\
\hline
\end{tabular}

\begin{tabular}{|l|l|l|}
\hline \multicolumn{3}{|l|}{ ALTERNATIVE } \\
\hline G & H & I \\
\hline N90 2..3 MW & \\
\hline OPTION 1 & OPTION 2 & OPTION 4 \\
\hline
\end{tabular}

\section{WIND RESOURCES}

One of the main factors for the construction of a wind farm is determining annual energy production. It is already known that the wind farms that have interest in this study are good sites for wind energy; indeed, they were among the first farms in Galicia.

To start with, a comparison was made of various wind generator models with similar features in terms of power, specifically the N80 at 2.5 MW and N90 at 2.3 MW from Nordex and the B80 at $2.3 \mathrm{~kW}$ from Bonus.
Table 2: Wind generator models

\begin{tabular}{|l|l|l|l|l|}
\hline Model & \multicolumn{4}{|l|}{ N80 2.5MW } \\
\hline Tower height (m) & $\mathbf{6 0}$ & $\mathbf{8 0}$ & $\mathbf{1 0 0}$ & $\mathbf{1 0 5}$ \\
\hline Rotor diameter (m) & 80 & 80 & 80 & 80 \\
\hline
\end{tabular}

\begin{tabular}{|l|l|l|}
\hline Model & \multicolumn{2}{|l|}{ B80 2.3MW } \\
\hline Tower height (m) & $\mathbf{6 0}$ & $\mathbf{8 0}$ \\
\hline Rotor diameter (m) & 82,4 & 82,4 \\
\hline
\end{tabular}

\begin{tabular}{|l|l|l|l|}
\hline Model & \multicolumn{3}{|l|}{ N90 2.3MW } \\
\hline Tower height (m) & $\mathbf{8 0}$ & $\mathbf{1 0 0}$ & $\mathbf{1 0 5}$ \\
\hline Rotor diameter (m) & 90 & 90 & 90 \\
\hline
\end{tabular}

However, for the calculation to be practical, it is necessary to compare models with a tower height of 80 $\mathrm{m}$, the common size of the three models. The highest ones are lattice towers, which means greater safety for future maintenance work.

As the new height $(80 \mathrm{~m})$ differs from the one for which the wind speeds were taken, a new conversion has to be carried out. Thus, the speed for the new height is 10.73 $\mathrm{m} / \mathrm{s}$.

Table 3: Results for the models with a $80 \mathrm{~m}$ tower

\begin{tabular}{|l|l|l|l|}
\hline Model & $\begin{array}{l}\text { N80 } \\
2 . .5\end{array}$ & $\begin{array}{l}\text { B80 } \\
2.3 ~ M W\end{array}$ & $\begin{array}{l}\text { N90 } \\
2.3 ~ M W\end{array}$ \\
\hline Tower height (m) & $\mathbf{8 0}$ & $\mathbf{8 0}$ & $\mathbf{8 0}$ \\
\hline Rotor diameter (m) & 80 & 82 & 90 \\
\hline $\begin{array}{l}\text { Input power (W/m } \\
\text { area) }\end{array}$ & 1.347 & 1.347 & 1.347 \\
\hline $\begin{array}{l}\text { Max. speed input power } \\
\text { (m/s) }\end{array}$ & 17 & 17 & 17 \\
\hline $\begin{array}{l}\text { Av. speed wind at hub } \\
\text { height }\end{array}$ & 11 & 11 & 11 \\
\hline $\begin{array}{l}\text { Power at output (W/m } \\
\text { rotor area) }\end{array}$ & 240 & 224 & 199 \\
\hline $\begin{array}{l}\text { Energy produced } \\
\text { (kWh/m } / \text { year) }\end{array}$ & 2,104 & 1,964 & 1,744 \\
\hline $\begin{array}{l}\text { Energy produced } \\
\text { (kWh/year) }\end{array}$ & $\mathbf{1 0 , 5 7 5}$ & $\mathbf{1 0 , 4 7 1}$ & $\mathbf{1 1 , 0 9 8}$ \\
\hline \begin{tabular}{l} 
Load factor (\%) \\
\hline
\end{tabular} & 48 & 52 & 55 \\
\hline
\end{tabular}

One might at first think that model $\mathrm{N} 80$ at $2.5 \mathrm{MW}$ would have a higher production. However, this is not the case, as shown in the table below. The N90 at $2.3 \mathrm{MW}$ has a larger rotor diameter, which would mean a higher annual production. 
Taking into account this calculation and using annual production as the criterion, it is concluded that the wind generator model chosen will be the N90 2.3MW from Nordex. Its annual production would be $11,097,610$ $\mathrm{kWh} /$ year, far above that of the original generators.

With the same programme, energy production is also calculated (kWh/year) for each model. The results are presented on table 4 .

\section{VIABILITY STUDY}

To find out which alternative is the most economically viable, it will be necessary to take into account the recovery period for each. In this way, the best alternatives are $\mathrm{C}$ and $\mathrm{G}$, whose recovery periods are five years, as well as $\mathrm{H}$ and $\mathrm{I}$, at four years, as shown below:

Table 4: Summary of the results

\begin{tabular}{|l|c|c|c|c|c|c|c|c|c|}
\cline { 2 - 10 } \multicolumn{1}{c|}{} & \multicolumn{10}{c|}{ Recovery period (years) } \\
\hline Alternative & A & B & C & D & E & F & G & H & I \\
\hline P. w/o financing & 8 & 7 & 7 & 10 & 9 & 8 & 7 & 6 & 6 \\
\hline P. financed & 8 & 6 & 5 & 9 & 9 & 8 & 5 & 4 & 4 \\
\hline
\end{tabular}

After the viability study for nine alternatives is done, it can be concluded that, in economic terms, alternative $\mathrm{G}$ stands out. $\mathrm{C}, \mathrm{H}$ and $\mathrm{I}$ require a new transmission licence, difficult to obtain. Alternative $G$ has the best recovery period and does not require a transmission licence.

Another factor is project financing, which may or may not be obtained. If financing is not sought, the recovery period would be seven years, whereas it is reduced to five with financing. For a later sensitivity analysis, a financed project will be examined so that a briefer recovery period is needed.

Alternative G, with the lower recovery period (five years), will be studied. Its profitability would be $29.16 \%$, and, moreover, it does not require a new transmission licence. This alternative would entail a total contract cost of $65 \mathrm{M} €$.

As mentioned earlier, alternative $\mathrm{G}$ is the NORDEX N90 2.3 MW generator.

Although it stands out in the economic viablity study, technical results also have to be taken into account, under the heading Wind Energy Resources. Here it is also concluded that the N90 2.3 MW model is the most suitable.

\section{SENSITIVITY ANALYSIS}

Together, the increase in energy sold, the average rate and the financing percentage make the project more viable. In other words, the Net Current Value and Internal Profitability Rate go up, while the recovery period is reduced. Nonetheless, increases in implementation costs, exploitation costs and the interest rate weaken the project's viability.

The viability analysis indicates the variables that have the greatest influence on the results are, above all, the quantity of energy sold each year, and, to a lesser extent, although still more influential than other variables, variations in the average rate. These two variables, therefore, are the ones to take into account when making final decisions.

Figure 1: Influence on the input variables on those for output
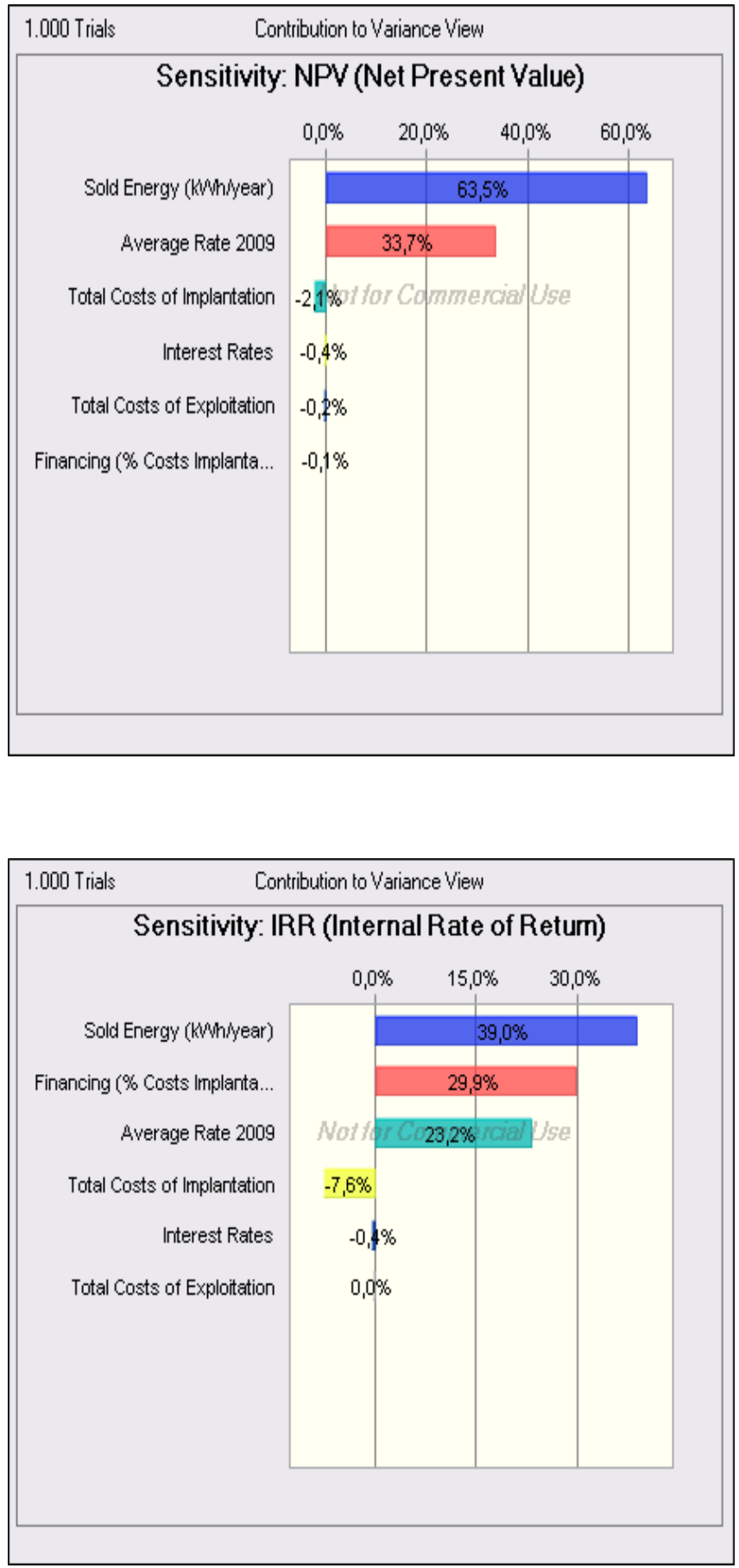


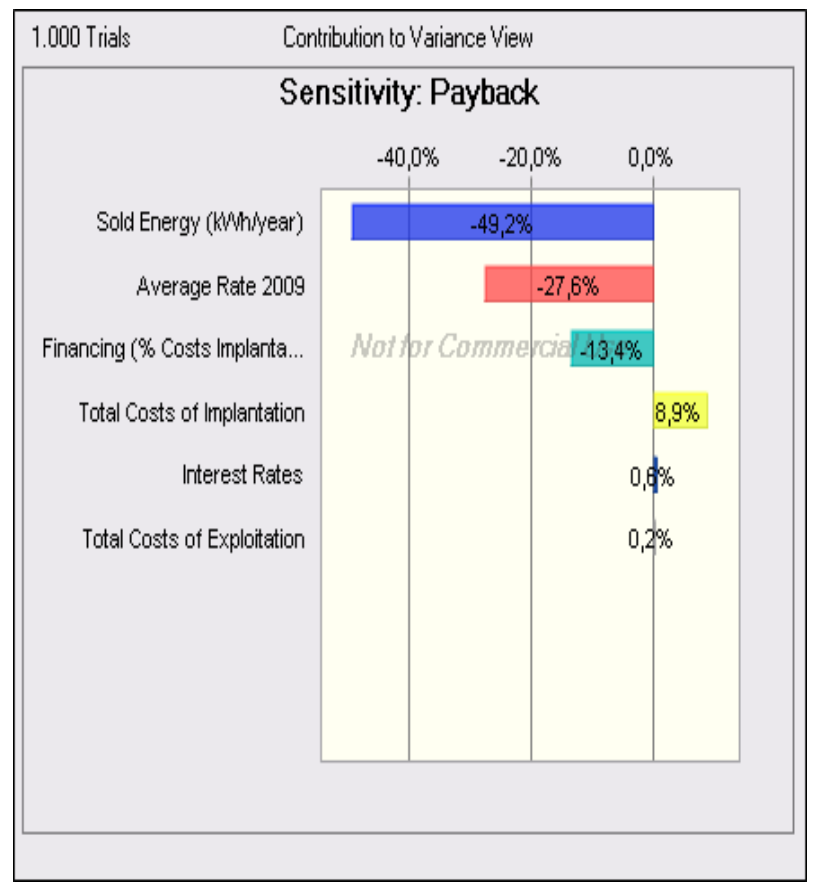

\section{CONCLUSIONS}

A number of advantages have been determined in the present project; these benefit both the community and the company:

- Environmental: There is a significant reduction in the number of wind generators, so that the visual and acoustic impact is also lessened. This form of energy is cleaner than others.

- Economic: The original generators are sold for scrap or to another country, perhaps in Eastern Europe. The copper content of the cabling can be sold. It is also possible to exploit the original roadways and foundations, which, once broken up, can be used for the farm's expansion. With the various rates, the productivity and earnings will increase; in the future, repowered farms may receive a premium.

The change from 124 for $330 / 325 \mathrm{~kW}$ to 18 for $2.3 \mathrm{MW}$ means an annual increase of $82 \mathrm{GWh}, 6.6 \mathrm{M} €$ more a year.

There are strong indications that repowering is a profitable endeavour, whose costs can be recovered in five years. This is mainly due to the sharp increase in the production of each generator or, rather, the more efficient exploitation of the wind at the site.

\section{References}

IEC 61400 - 1.Wind Turbines - Part 1: Design requirements. November 2005.

IEC 61400 - 11. Wind Turbine generator systems - Part 11: Acoustic noise measurement techniques. November 2006.
IEC 61400 - 12 - 1. Wind Turbines - Part 12-1: Power performance measurements of electricity producing wind turbines. November 2006.

IEC/TS 61400 - 14. Wind Turbines - Part 14: Declaration of apparent sound power level and tonality values. Marzo de 2005.

IEC 61400 - 21. Wind Turbines - Part 21: Measurement and assessment of power quality characteristics of grid connected wind turbines. Agosto de 2008.

Ackermann, T.: “Wind power in power systems". Ed. John Wiley \& Sons. Chichester, 2005.

Burton, T.: “Handbook of wind energy". Ed. John Wiley \& Sons. Chichester, 2001.

Castro Gil, M.; Cruz Cruz, I.; Sánchez Naranjo, C. : “Energía Eólica”. Ed. Progensa. Sevilla, 2006.

Escudero López, J.M.: “Manual de Energía Eólica: investigación, diseño, promoción, construcción y explotación de distintos tipos de instalaciones". Ed. Mundi-Prensa. Madrid, 2004.

Hernández Gonzálvez, C.: “Basic aspects for application of wind energy". IDAE. Madrid, 1994.

Maxwell, J.F.: "Wind energy explained theory, design and application”. Ed. John Wiley \& Sons. New York, 2002.

Le Gouriérès, D.: “Energía eólica: teoría, concepción y cálculo práctico de las instalaciones”. Ed. Masson. Barcelona, 1983. 